\title{
DEATH ANXIETY AND SLEEP QUALITY IN PATIENTS WITH IMPLANTABLE CARDIOVERTER DEFIBRILLATORS
}

\author{
MEDIHA SERT ${ }^{1}$ and Zeynep ÖZER ${ }^{2}$ \\ ${ }^{1}$ Akdeniz Üniversitesi \\ ${ }^{2}$ Akdeniz University
}

July 16, 2020

\begin{abstract}
Background: Implantable cardioverter defibrillators (ICD) are an effective therapy method for the prevention of sudden cardiac deaths but, it may cause certain psychosocial problems in patients. Although the patients are especially under the risk of death anxiety and sleep disorders, there are no studies that discuss these phenomena together. This research was a descriptive study that aimed to examine the levels of death anxiety and sleep quality as well as their relationship in patients with ICD. Methods: The research was conducted between September 2018-February 2019 with 88 patients. The data were obtained by using the Patient Information Form, Pittsburgh-Sleep-Quality-Index and Templer Death-Anxiety-Scale. The data were analyzed with Shapiro-Wilk test, t-test, chi-squared test, Mann-Whitney-U test and variation analysis. Results: Death anxiety levels were higher in females under 50 years of age $(\mathrm{p}<0.001)$, and sleep quality levels were lower in patients with low economic status $(\mathrm{p}<0.001)$. Also, ICD shocks increased anxiety levels and significantly decreased sleep quality levels $(\mathrm{p}<0.05)$. The anxiety and problems related to ICD increased death anxiety significantly $(\mathrm{p}<0.05)$, and sleep quality decreased due to the increase in death anxiety levels, but this wasn't statistically significant. Conclusion: ICD is associated with high levels of death anxiety and poor sleep quality in patients in Turkey. This study results are expected to promote biopsychosocial support for patients by planning proper interventions. In order to distinguish the effects of comorbid conditions and cultural traits on ICD experiences, it's recommended that the results of the study are examined with future studies and different populations.
\end{abstract}

\section{ABSTRACT}

Background: Implantable cardioverter defibrillators (ICD) are an effective therapy method for the prevention of sudden cardiac deaths but, it may cause certain psychosocial problems in patients. Although the patients are especially under the risk of death anxiety and sleep disorders, there are no studies that discuss these phenomena together. This research was a descriptive study that aimed to examine the levels of death anxiety and sleep quality as well as their relationship in patients with ICD.

Methods: The research was conducted between September 2018-February 2019 with 88 patients. The data were obtained by using the Patient Information Form, Pittsburgh-Sleep-Quality-Index and Templer DeathAnxiety-Scale. The data were analyzed with Shapiro-Wilk test, t-test, chi-squared test, Mann-Whitney-U test and variation analysis.

Results: Death anxiety levels were higher in females under 50 years of age $(\mathrm{p}<0.001)$, and sleep quality levels were lower in patients with low economic status $(\mathrm{p}<0.001)$. Also, ICD shocks increased anxiety levels and significantly decreased sleep quality levels $(\mathrm{p}<0.05)$. The anxiety and problems related to ICD increased death anxiety significantly $(\mathrm{p}<0.05)$, and sleep quality decreased due to the increase in death anxiety levels, but this wasn't statistically significant.

Conclusion: ICD is associated with high levels of death anxiety and poor sleep quality in patients in Turkey. This study results are expected to promote biopsychosocial support for patients by planning proper inter- 
ventions. In order to distinguish the effects of comorbid conditions and cultural traits on ICD experiences, it's recommended that the results of the study are examined with future studies and different populations.

Keywords: Death Anxiety, Implantable Cardioverter Defibrillator, Nursing, Sleep Quality. INTRODUCTION

Implantable cardioverter defibrillators (ICD) are electronic and programmable multifunctional devices that are implanted under the skin permanently. ${ }^{1,2}$ These devices are used in patients with arrhythmia that might cause death and advanced heart failure (HF). ${ }^{3}$ While the data regarding the implantation of these devices in the literature are limited, according to the World Survey of Cardiac Pacemaker and ICD conducted in 2009 , a total of 1,002,664 ICD implantations were performed within a year. It was reported that $74 \%$ of these implantations were new implants, while $26 \%$ were generator replacements. ${ }^{4}$ Beginning from 2010, a total of 850,068 ICD implants have been reported to be implanted within one year. ${ }^{5,6}$ According to the data from the European Society of Cardiology Report in 2014, ICD implantation rates per million population were the highest in Western Europe, followed by Northern and Southern European countries. The results also indicated that the need for arrhythmia therapies and therefore ICD implantation is on the rise. ${ }^{7}$

Although ICD implantation is 30-40\% effective in the reduction of mortality and morbidity, living with this device may lead to psychosocial problems in patients such as worry, anxiety and sleep disorders. ${ }^{8}{ }^{9}$ Patients with ICD are reported to experience greater anxiety compared to the general population and other patient populations. ${ }^{10}$ Foreignness of the ICD to the body, thoughts about constantly living with the device, the fact that it works in situations that may result in death and its battery may run out may cause anxiety. Shock delivery is another feature of the device that increases anxiety levels. Especially the uncertainty of the timing, place and the sensation of the shock triggers concerns of receiving shocks in inappropriate times, losing consciousness and not being safe. This condition may cause several problems for individuals, particularly death anxiety and sleep problems. ${ }^{11,12}$

Death anxiety refers to the emotion related to the anticipation or awareness of death. Especially thinking that heart is more vital than other organs causes individuals with heart disease to have more death anxiety compared to other patient groups. ${ }^{13,14}$ An increase in anxiety levels affects patients negatively and leads to psychosocial problems alongside sleep disorders. ${ }^{13,15}$ According to the studies, $70 \%$ of individuals with heart diseases develop sleep disorders. ${ }^{11,16}$ Likewise, sleep problems have been shown to be prevalent among patients with ICD. ${ }^{17}$ Sleep is an essential function that affects the quality of life, physical and mental well-being of individuals. For this reason, it is important to assess the levels of sleep quality and death anxiety in patients who have heart disease, particularly patients with ICD. Nurses have important roles and responsibilities in planning appropriate interventions to reduce anxiety levels, particularly death anxiety, and to improve sleep quality. Results of this study may be useful in raising awareness about the death anxiety and sleep quality levels of ICD patients and improving nursing care by planning appropriate interventions to prevent potential complications. In addition, this study may further contribute to the literature by helping to examine the death anxiety levels from previous studies about ICD in the Turkish population and the relationship between these anxieties and sleep quality.

\section{METHODS}

\subsection{Study Design and Aim}

This was a descriptive study conducted to determine the levels of death anxiety and sleep quality, and to examine their relationship in patients with ICD.

\subsection{Participants and Sampling}

The research was conducted with patients who came for routine battery follow-up at a university hospital and who met the inclusion criteria. The study was carried out between September 2018 and February 2019. The research population consisted of 113 patients who received ICD implantation in the last year. The sample size was determined to be 88 patients with $95 \%$ confidence interval, $80 \%$ power and $5 \%$ Type 
I error. The inclusion criteria for the study were determined as being 18 years old and over, having had ICD implantation, having no cognitive and communication impairments, and agreeing to participate in the study. The exclusion criteria were patients who had implanted devices other than ICD and who refused to participate in the study.

\subsection{Data Collection}

The data were collected by personal and face-to-face interview method. The preliminary application of the study was carried out with four patients who met the inclusion criteria between September 2018 and February 2019 after obtaining the necessary permissions from institutions and the hospital ethics committee. The patients who participated in the preliminary application were not included in the sample of the study. ICD patients who arrived at the clinic for routine battery follow-ups were first briefly informed about the subject and the application method of the research, and then they were invited to the study. Written consent was obtained from patients who agreed to participate in the study. Interviews were conducted in a clinic room where patients were able to feel comfortable. Interviews took approximately 15-20 minutes. During the data collection stage of the research, Patient Information Form, Pittsburgh Sleep Quality Index (PSQI) and Templer Death Anxiety Scale (DAS) were used.

Templer Death Anxiety Scale

DAS developed by Templer in 1970 for measuring death anxiety ${ }^{18}$ is a 2-point Likert type scale consisting of 15 items. Internal consistency of the scale was reported to be 0.76 . The scale was adapted to Turkish by Şenol (1989) and the internal consistency was calculated to be 0.72 by Cronbach's alpha value. Akça and Köse (2008) also adapted the scale and found the internal consistency value to be 0.75 according to Kuder Richardson-20 formula. In the scale every "yes" is given "one", every "no" is given "zero" point, and only the five items between 10-14 are calculated as reverse patterns. The total score constitutes death anxiety score. The scores to be obtained from the scale range between 0 and 15. Death anxiety levels are considered to be "mild" between zero and four points, "moderate" between five and nine points, "severe" between 10-14 points and "panic" at 15 points. The level of death anxiety increases with the score. ${ }^{19,20}$

Pittsburgh Sleep Quality Index

Pittsburgh sleep quality index was developed by Buysse et al. (1989). Its validity and reliability were assessed by Ağargün et al. (1996). It determines the sleep quality levels of the patients within the last month. Cronbach's Alpha internal consistency value of the scale was reported to be 0.80 . In total, it contains 24 questions and 20 items, the last two of which are not included during the evaluation, since they are answered by the patients' partner or roommates. 18 items included in the evaluation consist of seven different sub-items, which are scored between 0-3 points. The higher the score, the lower the sleep quality. ${ }^{21,22}$

While assessing the scale, three of the components are scored with one question, while four are scored with the total rating of a few questions. In addition, the fourth question is included in scoring two separate components. The total score of the components forms the scale score. The scale score varies between 0-21. Five points and more indicate poor sleep quality, while points less than five indicate good sleep quality. ${ }^{21,22}$

\section{Data Analysis}

While evaluating the data, SAS 9.4 package software was used for statistical analysis. The obtained data were firstly evaluated through descriptive statistics. Quantitative variables were displayed as mean and standard deviation, while qualitative variables were displayed as numbers and percentages. The conformity of the data to normal distribution was evaluated by Shapiro-Wilk test and it was found that it did not exhibit normal distribution. Non-parametric tests were used in statistical analysis, and Mann-Whitney U test was used for two-category variables. Mean and standard deviations of scale expressions, sub-dimensions and general scores of the scale were presented in tables. The relationship between the general scores of the scale and the mean scores of the sub-dimensions was calculated by the correlation coefficient. The statistical significance level was set at 0.05 for the entire study. 


\section{RESULTS}

\subsection{Demographics and Disease Data}

The mean age of the patients who participated in the study was $61.90+12.52$. Most of the participants were male, married and lived with their nuclear families. In addition, patients were mostly primary school graduates, retired, and of middle economic status. The ICD was implanted to $56.8 \%$ of the patients due to HF. More than half of the patients had The New York Heart Association (NYHA) Class II HF symptoms. Patients' ejection fraction (EF) values varied between 10-60\%, while the average EF value was $31.58 \%$. More than half of the patients had chronic diseases, mostly hypertension. The duration of ICD use was usually between 13-36 months. Findings regarding the patients' identifying characteristics are displayed in Table 1.

Common symptoms reported by most patients were chest pain, chest tightness, dizziness, breathlessness, getting exhausted quickly and sleep problems. Especially sleep problems were reported as a frequently recurrent symptom. Symptoms experienced by the patients in the last six months were determined as follows in descending order: quickly getting exhausted, breathlessness, sleep problems, dizziness, shortness of breath, palpitations, chest pain, chest tightness and fainting.

Among the problems related to ICD, the most frequent problems were found to be death anxiety, experiencing stimulation/cardioversion and shock, whereas the least encountered problem was avoiding driving due concerns of being shocked. $37.5 \%$ of the patients who participated in the study experienced shock at least once. Among the patients who experienced shock, $33.3 \%$ experienced it once, $36.4 \%$ twice, $21.2 \%$ three times and $9.1 \%$ four or more times. In addition, it was found that the patients who experienced shocks also suffered from the sensation of pain related to shocks. It was found that death anxiety was the most frequently experienced problem by the patients. It was also determined that uncertainty regarding the time of the shocks and worries about receiving shocks outside of home were among the major problems that accompanied death anxiety.

Whether the patients have had experience with shocks also affect the problems that occur due to ICD. It was found that patients who had received shocks experienced more problems, the patients who experienced shocks once suffered from constant stress due to shocks and worried about the loss of consciousness during the shocks more. It was determined that the problems of the patients who experienced three or more shocks were less developed. The distribution of problems experienced by patients due to ICD is demonstrated in Figure 1 according to experiences of being shocked. In descending order, anxiety about the sensation of pain due to shocks, loss of consciousness at the time of shock, death and uncertainty about the future were found to be higher in patients who experienced shock, and this was statistically significant $(\mathrm{p}<0.05)$.

It was determined that all the patients who experienced shocks had the problem of driving avoidance due to shock anxiety, and it was statistically significant $(\mathrm{p}<0.001)$. It was found that lack of sexual drive due to shock anxiety was higher in patients who underwent shocks, that the number of shocks did not affect this anxiety, and the relationship between being shocked and this problem was significant $(\mathrm{p}<0.05)$. It was determined that experiencing stress and sleep problems due to shock anxiety was more severe in patients who underwent shock, and the relationship between these problems and experience of being shocked was statistically significant $(\mathrm{p}<0.01)$. In the patients who did not experience shock, the major issues were concerns about battery running out and device failing to work, and the uncertainty of sensation and timing of the shock. The most common problems that caused constant stress can be listed as, in descending order, death anxiety, uncertainty of shocking time, receiving shocks outside home, anxiety that the battery will run out, the worry that the device will fail to work, and experiencing constant sleep problems due to shock.

\subsection{Findings Regarding Death Anxiety and Sleep Quality}

The distribution of DAS, PSQI and PSQI subcomponents' mean scores of the patients participating in the study are presented in Table 2. Global PSQI score ranges between 0-21 points. The range in our study was determined to be between the range of $2-17$ points (Mean $=8.44 ; \mathrm{SD}=2.90 ; \mathrm{N}=88$ ). In our study, 7 patients' sleep quality was found to be good, while it was found to be poor in 81 patients. When the 
PSQI mean scores regarding the socio-demographic characteristics of the patients participating in the study were examined, the mean scores of PSQI were found to be higher in patients who were under the age of 50, married, primary school graduate, who lived with extended family, unemployed or retired. In addition, the PSQI mean scores of the males participating in the study were found to be higher than females, but all these differences were not significant. It was determined that the mean scores of PSQI were higher in patients who had poor economic status compared to the groups with different economic status and that these differences were statistically significant $(\mathrm{p}<0.001)$. PSQI subcomponent scores demonstrated that sleep efficiency subcomponents in patients with HF diagnosis related to ICD mean scores were higher than other diagnosis groups. The sleep disturbance subcomponent was found to be higher in Class IV patients according to NYHA classification compared to other class levels. These differences between the mean scores for both subcomponents were found to be statistically significant $(\mathrm{p}<0.05)$.

Global DAS score ranges from 0 to 15 , and the DAS score in our study ranged from 1 to 14 points (Mean = 7.47; $\mathrm{SD}=3.97 ; \mathrm{N}=88$ ). Among the patients who participated in our study, 26 had mild, 30 had moderate and 32 had severe death anxiety. Additionally, no patient was found to have death anxiety at panic level. It was determined that female patients in the study had a higher mean score of DAS compared to males and that this score difference was statistically significant $(\mathrm{p}<0.001)$. Likewise, in patients aged 50 and under and between 51-60 years of age, the DAS mean scores were higher in comparison to other groups, and these differences were statistically significant $(\mathrm{p}<0.001)$. Additionally, female patients who were single or who lived alone were found to have higher DAS scores than other groups, but no significant relationship was found. When the disease characteristics and scale scores of the patients were examined, the difference between the mean scores of PSQI and DAS was not found to be statistically significant.

When the relationship between the problems experienced by patients in our study and levels of sleep quality was examined, it was found that nearly all patients who suffered ICD-related problems had poor sleep quality. Dyspnea and sleep problems particularly were found to be statistically significantly linked to quality of sleep $(\mathrm{p}<0.05, \mathrm{p}<0.01$, respectively). It was also determined that the relationship between the shock experience and sleep quality levels was statistically significant $(\mathrm{p}<0.05)$.

When the problems experienced by the patients and the levels of death anxiety were examined, it was found that most of the patients who suffered from ICD- related problems had high levels of death anxiety; however, this was not found to be statistically significant. Nevertheless, it was determined that feelings of uncertain future, anxiety about lack of necessary shocks, the uncertainty of the sensation of receiving shock, pain linked to shock and concerns about losing consciousness during being shocked were found to be associated with the levels of death anxiety in a statistically significant way. $(\mathrm{p}<0.05)$. The anxiety of battery running out and device failing to work, the uncertainty of the timing of the shock, the anxiety about receiving shock outside of home, experiencing constant stress due to death anxiety and shock anxiety were found to be statistically highly significant $(\mathrm{p}<0.001)$ with levels of death anxiety; concerns of experiencing pain due to shocks and uncertain future were determined to be statistically significant $(\mathrm{p}<0.01)$ in regards to uncertainty anxiety problems. It was found that there was a statistically significant relationship between anxiety about not receiving shocking/stimulation when necessary, the uncertainty of shocking sensation, and problems of losing consciousness during shock and death anxiety levels $(\mathrm{p}<0.05)$.

When the relationship between death anxiety and sleep quality scores of the patients were assessed, it was determined that $42.9 \%$ of the patients who experienced mild death anxiety had good sleep quality, while $34.5 \%$ of the patients who had moderate death anxiety and $37 \%$ of the patients who suffered from severe death anxiety had poor sleep quality. In the overall study, it was found that $36.4 \%$ of the patients suffered from severe death anxiety and $92.4 \%$ had poor sleep quality; however, there was no significant relationship between the levels of sleep quality and death anxiety. These data demonstrate that as the death anxiety levels of the patients increased, their sleep quality levels decreased (Figure 2). When the correlations between death anxiety and sleep quality scores were examined, it was found that the correlation between PSQI and its subcomponents was moderate, positive and significant, whereas the correlation between DAS and PSQI with its subcomponents was weak, positive and not significant (Table 3). 


\section{DISCUSSION}

This study examined the relationship between death anxiety and sleep quality levels experienced by patients with ICD. This study is substantial and novel in terms of examining the effects of ICD implementation on patients in Turkish population which has not been studied adequately before as well as examining the relationship between death anxiety levels and sleep quality levels of patients with ICD, which is also very limited in the literature.

\subsection{Examination of Sociodemographic and Disease-Related Characteristics}

In our study, the effects of patients' sociodemographic and disease-related characteristics, problems experienced related to ICD and physical symptoms on death anxiety and sleep quality levels were also examined. Neurohormonal and degenerative tissue changes occur in the cardiovascular system due to aging, which is one of the socio-demographic factors. These changes lead to arrhythmias by causing atrioventricular conduction delay, altered heart rate and decreased response to exercise. ${ }^{23,24}$ High average of age in our sample was associated with this condition. Additionally, higher number of male patients in the sample was associated with vascular, metabolic and hemodynamic protective effects of estrogen in the pre-menopausal period for females. ${ }^{25}$

This study demonstrated that young male patients with poor economic status had lower sleep quality levels compared to patients with different sociodemographic backgrounds. Similar to the results of our study, the research conducted by Habibovic et al. (2018) documented that $67 \%$ of ICD patients suffered from sleep problems, which decreased to $57 \%$ over time, but this value was still significant. Moreover, it was demonstrated that young male patients suffered more sleep problems. This indicates that sleep problems in patients are not solely caused by ICD-related problems.

The results of our study showed that that single and young female patients had higher levels of death anxiety than other socio-demographic patient groups. In most of the studies conducted on this subject, no difference between the genders was found regarding death anxiety. The studies that confirmed a difference reported that in line with our results, females experienced more death anxiety than males. ${ }^{26,27}$ This condition is linked to females' thinking about death more often. Likewise, it is predicted that death anxiety is a phenomenon specifically experienced by women and that women report more of their death anxiety compared to men; therefore, they develop higher levels of death anxiety. ${ }^{26,27}$ In a study conducted by Vazquez et al. ${ }^{28}$ (2008), it was found that female patients had higher levels of death anxiety, and this situation was statistically significant.

In contemporary western culture and Turkish society, death is defined as the inevitable, the end and the absence of existence. ${ }^{29,30}$ Death is the disappearance of the self; thus, these definitions indicate that death is understood as a negative and unwelcome phenomenon for the individuals. Death also has major effects on individuals' life experiences as a phenomenon. Thus, experiencing anxiety about death which is understood as an unwelcome phenomenon is inevitable ${ }^{30}$. Templer pointed out that patients' previous experiences with death influenced the anxiety of death, and there was no relationship between the ages of the patients and death anxiety levels. ${ }^{18}$ However, in most of the studies, similar to ours, levels of death anxiety were reported to be higher in younger patients. This is linked to regret and feelings of missing out on life. Hence, it is predicted that the elderly accept death and thus experience less death anxiety due to experiencing life to the fullest, psychological maturity and frequently encountering the deaths of their close ones. ${ }^{31,32}$ In another research conducted with ICD patients, death anxiety was found to be higher among patients under the age of $50 .^{28}$

Arrhythmias triggered by degeneration increased due to age may lead to various physical symptoms in patients. The results of our study showed that shortness of breath, chest pain, chest tightness and sleep problems were among the most frequently reported symptoms. Failure to maintain the circulation effectively and increased blood volume in the heart and the lungs during sleep trigger paroxysmal nocturnal dyspnea and orthopnea, which interfere with the patient's sleep by causing shortness of breath. Similarly, the use of diuretic drugs by patients diagnosed with HF is another factor that interferes with sleep due to the need 
to use the toilet. ${ }^{33,34}$ It has been reported that symptoms experienced by patients may also develop due to psychological problems such as anxiety and stress. ${ }^{35}$ In studies similar to ours, it was documented that the most frequently encountered symptoms were sleep problems and dizziness. ${ }^{36}$

Patients in our study reported various problems related to ICD following implantation. These problems were linked to ICD's shock feature, being dependent on a device for survival and the device interfering when life threatening arrhythmia occurs. ${ }^{11,12}$ The results of our study demonstrated that patients who reported these problems had poor sleep quality and suffered from severe death anxiety. Moreover, these problems were found to be significantly related to the experience and the number of shocks. Particularly in patients who had experienced shocks, the reason of higher levels of death anxiety and lower levels of sleep quality were determined as the anxiety about receiving shock again. ${ }^{37,38}$ It was determined that patients who had not experienced shocks also worried about the uncertainty and ambiguity of getting shock.

Studies conducted demonstrated that patients who had received shocks experienced problems 2.2 times more compared to those who had not, suffered from anxiety 1.58 times more, and patients who encountered ICD related problems were 4.98 times more likely to experience anxiety than those who did not. ${ }^{37,38}$ These problems are linked to psychological theories such as learned helplessness, classical conditioning and cognitive appraisal models. ${ }^{39}$ Moreover, lack of coping strategies due to not experiencing shocks before is predicted to be significant. Death anxiety has been shown to arise due to encountering death. ${ }^{40}$ These results support the need to approach individuals based on their experiences of shock and to plan interventions accordingly. It is predicted that problems can be minimized by informing patients and implementing a proper management plan.

\subsection{Examining the Relationship Between Death Anxiety and Sleep Quality}

The results of our study on the relationship between death anxiety and levels of sleep quality demonstrated that patients' sleep quality decreased as death anxiety increased. When the correlations between death anxiety and sleep quality scores were evaluated, the correlation between PSQI and its subcomponents was found to be moderate, positive and significant. The correlation between the subcomponents of DAS and PSQI was found to be positive, weak and not significant. It is predicted that this may occur due to uncontrollable physical and environmental factors that influence the patients. It also makes it difficult to distinguish anxiety and sleep problems related to comorbidity of patients from ICD experiences.

In another study that examined the relationship between sleep problems and psychological problems, parallel to our study, it was found that sleep problems were linked to psychological problems, that psychological problems accompanied sleep problems for $40-50 \%$ of the patients, and that anxiety levels were 17 times higher in patients with sleep disorders. ${ }^{41}$ Moreover, it was reported that in patients with poor sleep quality, levels of anxiety and reaction to negative stimuli increased, and that this condition created a vicious cycle by causing cardiovascular risk factors and diseases. ${ }^{17,42}$ Similarly, it was demonstrated that $24-87 \%$ of ICD patients experienced anxiety related to ICD, and accompanying sleep problems had a negative effect on the patients' lives and treatments. ${ }^{43}$

\subsection{Study Limitations}

The research is a cross-sectional study, consequently, the findings are limited to the city and the center where the research was carried out. Moreover, the findings are explanatory rather than predictive. Patients' existing cardiovascular diseases and comorbidity make distinguishing ICD experiences more challenging. Additionally, it was not possible to distinguish the effects of sleep problems such as hypersomnia or sleep apnea on patients' sleep quality levels.

\section{CONCLUSION}

In our study, it was found that ICD caused death anxiety and poor sleep quality, and that these two phenomena could have an effect on each other. Increased insomnia and anxiety may trigger cardiovascular diseases, which may trigger levels of sleep quality and death anxiety. This situation can turn into a vicious cycle that intensifies over time. Thus, this study demonstrated that these two phenomena should be evaluated together 
by healthcare professionals for each patient. The results demonstrated that levels of death anxiety and sleep quality changed based on experiences as well. Thus, it is recommended that both of these phenomena be evaluated following cardiac situations and during routine checks that are performed at least once a year. In addition, young female patients in terms of death anxiety, and young male patients in terms of sleep quality, and individuals with low economic status and individuals with ICD problems should be evaluated with priority and more frequently due to being in the risk group. It is expected that informing patients about how ICD works, its functions, shocks, and coping with anxiety and thus creating a proper management plan will contribute to achieving an effective and holistic nursing care.

\section{REFERENCES}

1. Kikkenborg Berg S, Støier L, Moons P, et al. Emotions and health: findings from a randomized clinical trial on psychoeducational nursing to patients with İmplantable Cardioverter Defibrillator. J Cardiovasc Nurs. 2015;30(3):197-204. doi:10.1097/JCN.0000000000000132

2. Al-khatib SM, Ackerman MJ, Gillis AM, et al. 2017 AHA/ACC/HRS Guideline for management of patients with ventricular arrhythmias and the prevention of sudden cardiac death.; 2017. doi:10.1161/CIR.0000000000000549.

3. Ketilsdottir A, Albertsdottir HR, Akadottir SH, et al. The experience of sudden cardiac arrest: Becoming reawakened to life. Eur J Cardiovasc Nurs. 2014;13(5):429-435. doi:10.1177/1474515113504864

4. Mond HG, Proclemer A. The 11th World Survey of Cardiac Pacing and Implantable CardioverterDefibrillators: Calendar Year 2009-A World Society of Arrhythmia's Project. Pacing Clin Electrophysiol. 2011;34(8):1013-1027. doi:10.1111/j.1540-8159.2011.03150.x

5. Hammill SC, Kremers MS, Stevenson LW, et al. Review of the Registry's Fourth Year, Incorporating Lead Data and Pediatric ICD Procedures, and Use as a National Performance Measure. Hear Rhythm. 2010;7(9):1340-1345. doi:10.1016/j.hrthm.2010.07.015

6. Kremers MS, Hammill SC, Berul CI, et al. The National ICD Registry Report: Version 2.1 including leads and pediatrics for years 2010 and 2011. Hear Rhythm. 2013;10(4). doi:10.1016/j.hrthm.2013.01.035

7. Pekka Raatikainen MJ, Arnar DO, Zeppenfeld K, et al. Statistics on the use of cardiac electronic devices and electrophysiological procedures in the European Society of Cardiology countries: 2014 report from the European Heart Rhythm Association. Eur Eur Soc Cardiol. 2015;17:i1-i75. doi:10.1093/europace/euu300

8. Wilson MH, Engelke MK, Sears SF, et al. Disease-specific quality of life - Patient acceptance: Racial and gender differences in patients with implantable cardioverter defibrillators. J Cardiovasc Nurs. 2013;28(3):285293. doi:10.1097/JCN.0b013e31824e072e

9. Moss AJ, Greenberg H, Case RB, et al. Long-Term Clinical Course of Patients After Termination of Ventricular Tachyarrhythmia by an Implanted Defibrillator. Circulation. 2004;110(25):3760-3765. doi:10.1161/01.CIR.0000150390.04704.B7

10. Karataş T, Polat Ü. Psychosocial nursing approach to the patients shocked intracardiac cardioverter defibrillator. Medeni Med J. 2015;30(1):51-55. doi:10.5222/MMJ.2015.051

11. Dickerson SS, Posluszny M, Kennedy MC. Help Seeking in a Support Group For Recipients Of İmplantable Cardioverter Defibrillators And Their Support Persons. Hear Lung J Acute Crit Care. 2000;29(2):87-96. doi:10.1067/mhl.2000.104138

12. Lewin RJ, Coulton S, Frizelle DJ, et al. A brief cognitive behavioural preimplantation and rehabilitation programme for patients receiving an implantable cardioverter-defibrillator improves physical health and reduces psychological morbidity and unplanned readmissions. Heart. 2008;95(1):63-69. doi: $10.1136 /$ hrt.2007.129890 
13. Beery TA, Sommers MS, Hall J. Focused Life Stories of Women With Cardiac Pacemakers. West J Nurs Res. 2002;24(1). http://journals.sagepub.com/doi/pdf/10.1177/01939450222045680. Accessed April $9,2018$.

14. Altunbaş G, Ercan S, Davutoğlu V, et al. Relationship of cardiovascular disease and depression. J Mood Disord. 2012;2(2):84-90. doi:10.5455/jmood.20120615043521

15. Balcı A, Enç N. The Effect of Audio-Visual Education Given to Coronary Angiography Patients over Physio- logical and Psychosocial Parameters. Turk Soc Cardiol Turkish J Cardiovasc Nurs. 2013;4(5):41-50. doi:10.5543/khd.2013.005

16. Burns JL, Serber ER, Keim S, et al. Measuring Patient Acceptance of Implantable Cardiac Device Therapy: Initial Psychometric Investigation of The Florida Patient Acceptance Survey. J Cardiovasc Electrophysiol. 2005;16(4):384-390. doi:10.1046/j.1540-8167.2005.40134.x

17. Habibovic M, Pedersen S, Schoormans D, et al. Sleep disturbance in patients with an implantable cardioverter defibrillator: Prevalence, predictors and impact on health status. Eur J Cardiovasc Nurs. 2018;17(5):390-398. doi:10.1177/1474515117748931

18. Templer DI. The construction and validation of a Death Anxiety Scale. J Gen Psychol. 1970;(82):165-177.

19. Şenol C. Anxiety and fears about death in the elderly living in institutions in Ankara province. 1989.

20. Akça F, Köse İA. Adaptation of Death Anxiety Scale (DAS): Validity and Reliability Studies. J Clin Psy. 2008;11:7-16.

21. Buysse DJ, Reynolds CF, Monk TH, et al. The Pittsburgh Sleep Quality Index: A New İnstrument For Psychiatric Practice And Research. Psychiatry Res. 1989;28(2):193-213. doi:10.1016/0165-1781(89)90047-4

22. Ağargün MY, Kara H, Anlar Ö. The Validity and Reliability of the Pittsburgh Sleep Quality Index. Turkısh J Psychiatry. 1996;7(2):107-115.

23. Zefirov TL, Svyatova N V, Ziyatdinova NI. A new insight into mechanisms of age-related changes in heart rate. Bull Exp Biol Med. 2001;131(6):518-522. http://www.ncbi.nlm.nih.gov/pubmed/11586394. Accessed May 22, 2019.

24. Berry C, Rankin A, Brady A. Bradycardia and tachycardia occurring in older people: investigations and management. Br J Cardiol. 2004;11:224-228.

25. Chen F-P. Hormone Therapy and Cardiovascular Disease. Taiwan J Obstet Gynecol. 2006;45(4):287-293. doi:10.1016/S1028-4559(09)60245-X

26. Templer DI, Lester D, Ruff CF. Fear of Death and Femininity. Psychol Rep. 1974;35(1):530-530. doi:10.2466/pr0.1974.35.1.530

27. Assari S, Moghani Lankarani M. Race and Gender Differences in Correlates of Death Anxiety Among Elderly in the United States. Iran J psychiatry Behav Sci. 2016;10(2):e2024. doi:10.17795/ijpbs-2024

28. Vazquez LD, Kuhl EA, Shea JB, et al. Age-Specific Differences in Women with Implantable Cardioverter Defibrillators: An International Multi Center Study. Pacing Clin Electrophysiol. 2008;31(12):1528-1534. doi:10.1111/j.1540-8159.2008.01223.x

29. Byock I. The Meaning and Value of Death. J Palliat Med. 2002;5(2):279-288.

30. Ergun P. Some of The Terms Related to Death in Turkish Culture International and Quarterly Journal of Cultural Studies, 25(100), 134-148.

31. Rasmussen CH, Johnson ME. Spirituality and Religiosity: Relative Relationships to Death Anxiety. OMEGA - J Death Dying. 1994;29(4):313-318. doi:10.2190/D1M9-3W6J-FY33-G3HQ 
32. Suhail K, Akram S. Correlates of death anxiety in Pakistan. Death Stud. 2002;26(1):39-50. doi:10.1080/07481180210146

33. Ponikowski P, Voors AA, Anker SD, et al. 2016 ESC Guidelines For The Diagnosis And Treatment Of Acute And Chronic Heart Failure The Task Force For The Diagnosis And Treatment Of Acute And Chronic Heart Failure Of The European Society Of Cardiology (ESC). Eur Heart J. 2016:891-975. doi:doi:10.1093/eurheartj/ehw128

34. Kasapoğlu ES, Enç N. A Guide for the Nurses in Care Management of Heart Failure. J Cardiovasc Nurs. 2017;8(16):35-44. doi:10.5543/khd.2017.35229

35. Arpacı F, Avdaş E, Doğruöz Ö, et al. A study into death anxiety at the elderly. Elderly Issues Research Journal. 2011;1(21):53-66. Retrieved from https://dergipark.org.tr/tr/pub/yasad/issue/21794/234241

36. Sneed N V, Finch N. Experiences of patients and significant others with automatic implantable cardioverter defibrillators after discharge from the hospital. Prog Cardiovasc Nurs. 1992;7(3):20-24. http://www.ncbi.nlm.nih.gov/pubmed/1297142. Accessed May 26, 2019.

37. Thylén I, Moser DK, Strömberg A, et al. Concerns about implantable cardioverter-defibrillator shocks mediate the relationship between actual shocks and psychological distress. Europace. 2016;18(6):828-835. doi:10.1093/europace/euv220

38. Thylén I, Moser DK, Strömberg A. Octo- and nonagenarians' outlook on life and death when living with an implantable cardioverter defibrillator: a cross-sectional study. BMC Geriatr. 2018;18(1):250. doi:10.1186/s12877-018-0942-9

39. Camm AJ, Sears SF, Todaro JF, et al. Examining the psychosocial impact of implantable cardioverter defibrillators: A literature review. Clin Cardiol. 1999;22(7):481-489. doi:10.1002/clc.4960220709

40. Mohsen Hussein NA, Thomas MA. Rehabilitation of patients with implantable cardioverter/defibrillator: a literature review. Acta Cardiol. 2008;63(2):249-257. doi:10.2143/ac.63.2.2029535

41. Taylor DJ, Lichstein KL, Durrence HH, et al. Epidemiology of Insomnia, Depression, and Anxiety. Sleep. 2005;28(11):1457-1464. doi:10.1093/sleep/28.11.1457

42. Pilcher JJ, Callan C, Posey JL. Sleep deprivation affects reactivity to positive but not negative stimuli. J Psychosom Res. 2015;79(6):657-662. doi:10.1016/j.jpsychores.2015.05.003

43. Sears SF, Todaro JF, Lewis TS, et al. Examining the psychosocial impact of implantable cardioverter defibrillators: A literature review. Clin Cardiol. 1999;22(7):481-489. doi:10.1002/clc.4960220709

\section{Hosted file}

Table1. ICD . docx available at https://authorea.com/users/343593/articles/470227-death-anxietyand-sleep-quality-in-patients-with-implantable-cardioverter-defibrillators

\section{Hosted file}

Table2. ICD . docx available at https://authorea.com/users/343593/articles/470227-death-anxietyand-sleep-quality-in-patients-with-implantable-cardioverter-defibrillators

\section{Hosted file}

Table3.ICD.docx available at https ://authorea.com/users/343593/articles/470227-death-anxietyand-sleep-quality-in-patients-with-implantable-cardioverter-defibrillators

\section{Hosted file}

Figure.1.ICD.docx available at https://authorea.com/users/343593/articles/470227-deathanxiety-and-sleep-quality-in-patients-with-implantable-cardioverter-defibrillators 


\section{Hosted file}

Figure.2.ICD.docx available at https://authorea.com/users/343593/articles/470227-deathanxiety-and-sleep-quality-in-patients-with-implantable-cardioverter-defibrillators 